\title{
A Traumatic Context Can Hide a Sexual Rape
}

\author{
Ammor FZ ${ }^{*}$, Rabiou $\mathrm{S}^{1}$, Issoufou $\mathrm{I}^{1}$, Belliraj $\mathrm{L}^{1}$, Harmouchi $\mathrm{H}^{1}$, Lakranbi $\mathrm{M}^{1}$, Ouadnouni $\mathrm{Y}^{1,2}$ and Smahi \\ $M^{1,2}$
}

${ }^{1}$ Department of Thoracic Surgery, CHU Hassan II Fes, Morocco

${ }^{2}$ Faculty of Medicine and Pharmacy, Université Sidi Mohamed Ben, Abdellah, Fez Morocco

*Corresponding author: Ammor FZ, Department of Thoracic Surgery, CHU Hassan II Fes, Morocco, Tel: 00212652090910, E-mail: Dr.a.ammor@gmail.com

Citation: Ammor FZ, Rabiou S, Issoufou I, Belliraj L, Harmouchi H, et al. (2018) A Traumatic Context Can Hide a Sexual Rape. J Case Rep Stud 6(5): 503. doi: 10.15744/2348-9820.6.503

Received Date: July 02, 2018 Accepted Date: October 29, 2018 Published Date: October 31, 2018

\begin{abstract}
Aeric syndrome during a multiple trauma reflects the severity of this latter, which made mention to extra thoracic or intra thoracic lesion. This requires a good diagnostic and therapeutic strategy. We report the case of a young patient admitted to emergency in an array of closed multiple traumas where the etiological diagnosis was rare and unknown.

This case highlights that a careful questioning and a good examination in admission can reveal earlier the diagnosis, the thing that was not well led in our case, because the patient was mute, anxious, and not cooperating making unnoticed rape history.
\end{abstract}

Keywords: Sexual assault; Subcutaneous emphysema; Multiple trauma; Pneumomediastinum; Pneumorachis

\section{Introduction}

Post traumatic aeric syndrome is characterized by the association of a: subcutaneous emphysema, pneumothorax, pneumomediastinum, pneumorachis, pneumoperitoneum.

This is a very rare pathological entity often secondary to closed trauma [1,2]. This syndrome in multiple trauma testifies the severity of the latter and evoke intrathoracic injury (tracheobronchial tree, esophagus, lung), or extrathoracic injury (crania facial, disruption of an intra-abdominal hollow organ) [3]. This requires an attentive diagnostic and therapeutic strategy to have an early and proper etiological diagnosis.

We report the case of a young patient admitted to emergency in a described below, clinical presentation without pneumothorax, result of aggression, leaving a multiple trauma, where the etiological diagnosis was rare and unknown.

\section{Observation}

A.L 16 years old, with any past medical history, admitted to the emergencies following an assault by slashing of multiple thoracoabdominal impact shots, having resulted a closed chest trauma and abdominal contusions.

The clinical examination on admission found a patient conscious, mute (Interrogation done with the family), normocardium at $67 \mathrm{Bat} / \mathrm{min}$, dyspneic with a respiratory rate at 20 cycles / min, $\mathrm{SaO} 2$ at 96\% under $2 \mathrm{l} / \mathrm{min}$ of O2 , diffuse fascio-cervicothoracoabdominal subcutaneous emphysema, without occulo-palpebral petechiae (Figure 1); the thoracic examination did not show any ecchymosis or parietal contusion, no pleural effusion syndroma, the abdomen was slightly sensitive in its entirety; with subcutaneous emphysema reaching the thigh.

The ECG showed sinus rhythm with no conduction disorder or repolarization. The frontal chest x-ray showed diffuse cervicothoracic subcutaneous emphysema, pneumo-mediastinum and pneumoperitoneum, without pneumo pericardium, nor pneumothorax, diaphragmatic dome in place; no rib fracture or lung contusion (Figure 2).

An abdominal ultrasound was impossible, being hampered by the presence of diffuse abdominal subcutaneous emphysema. A Thoraco-abdominopelvic CT found on the thoracic stage: diffuse cervico-thoracic subcutaneous emphysema associated with diffuse pneumo mediastinum, and pneumo rachis (Figure 3), without pneumothorax or rib or spinal fracture, with good integrity of the tracheobronchial tree and diaphragmatic cupolas (Figure 4); in the abdominal stage: Diffuse pneumoperitoneum with good integrity of the abdominal viscera was noted (Figure 5). Bronchial fibroscopy did not found a breach or a tracheobronchial rupture. 
Initial therapeutic management was limited to a nasal oxygenation associated to analgesic treatment and parenteral nutrition.

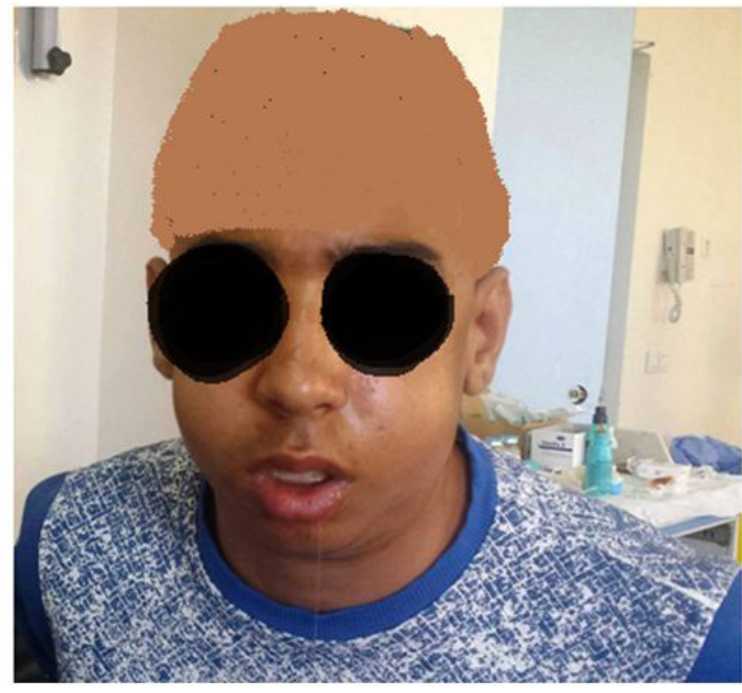

Figure 1: Diffuse cervico-thoracic subcutaneous emphysema reaching up to the occulo-palpebral region without petechiae

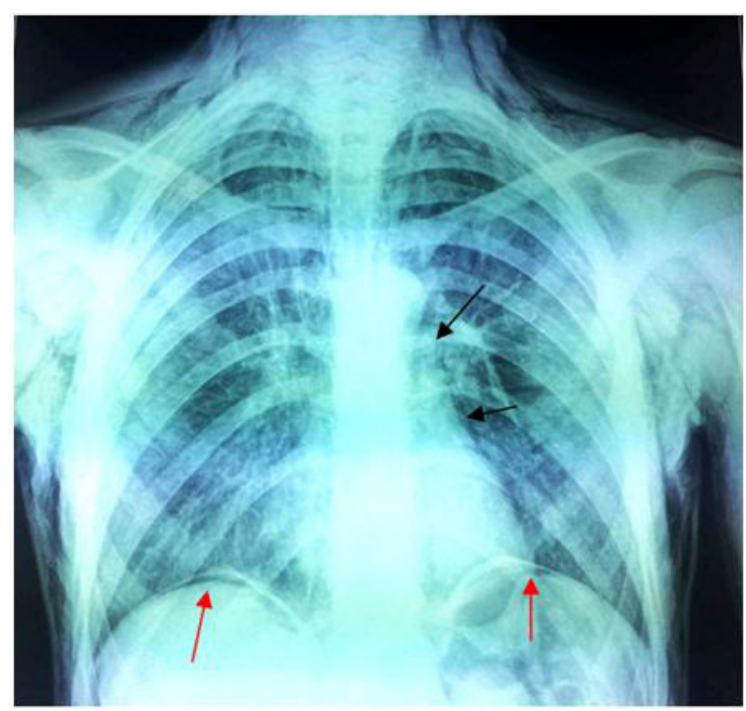

Figure 2: Frontal pulmonary radiography showing diffuse cervico-thoracic subcutaneous emphysema, associated with pneumomediastinum (black arrow) and Pneumoperitoneum (Red arrow), without rib fracture or pulmonary contusion, no pleural effusion syndrome

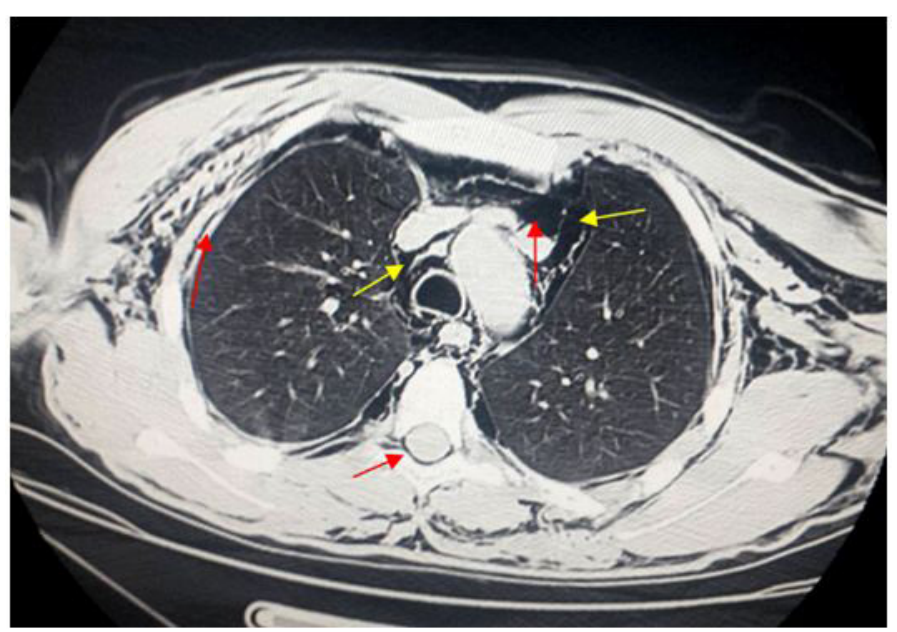

Figure 3: Thoracic CT scan axial section: thoracic stage: showing cervico-thoracic subcutaneous emphysema, with diffuse pneumomediastinum (yellow arrow), with pneumorachis (red arrow) 


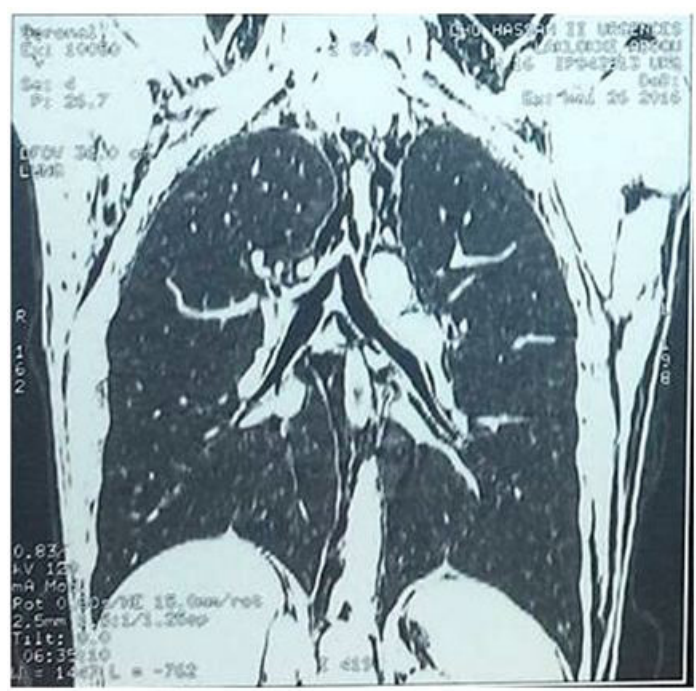

Figure 4: Thoracic CT scan sagittal section: Cervico-thoracic subcutaneous emphysema with pneumomediastinum, good integrity of the diaphragmatic cupolas and the tracheobronchial tree

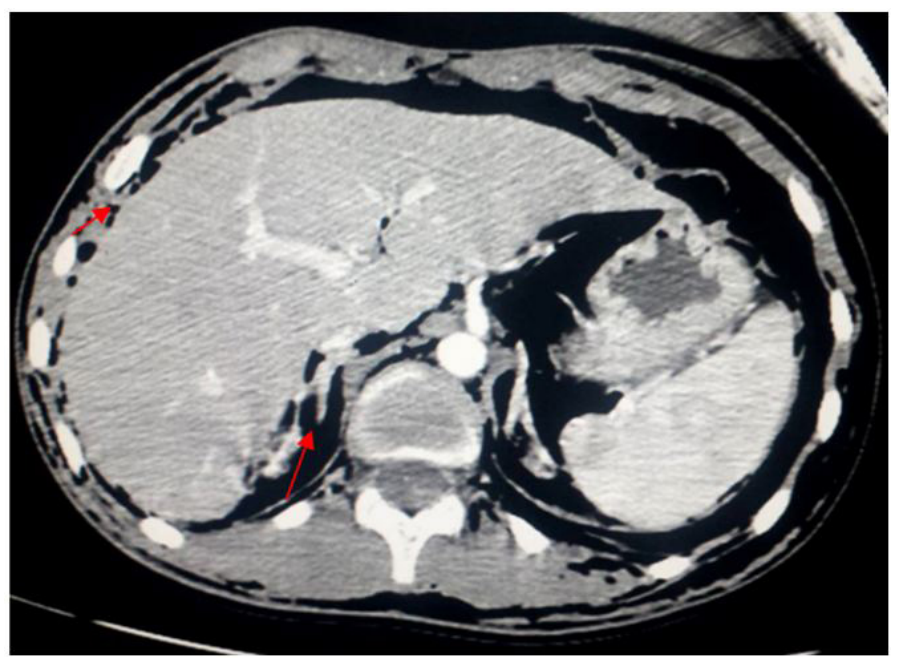

Figure 5: Abdominal CT: Axial section: Diffuse pneumoperitoneum (Red arrow), with abdominal subcutaneous emphysema

The evolution marked by regression of subcutaneous emphysema. The biological assessment was normal, except for an increase in white blood cells to $15000 / \mathrm{mm}^{3}$ and a $\mathrm{CRP}=40 \mathrm{mg}$. The onset of abdominal pain led us to repeat abdominopelvic CT but this time with pacification of the digestive organs rectally, which objectified a rectal fistula at $6 \mathrm{~cm}$ of the anterior retro-vesicle anal margin (Figure 6).

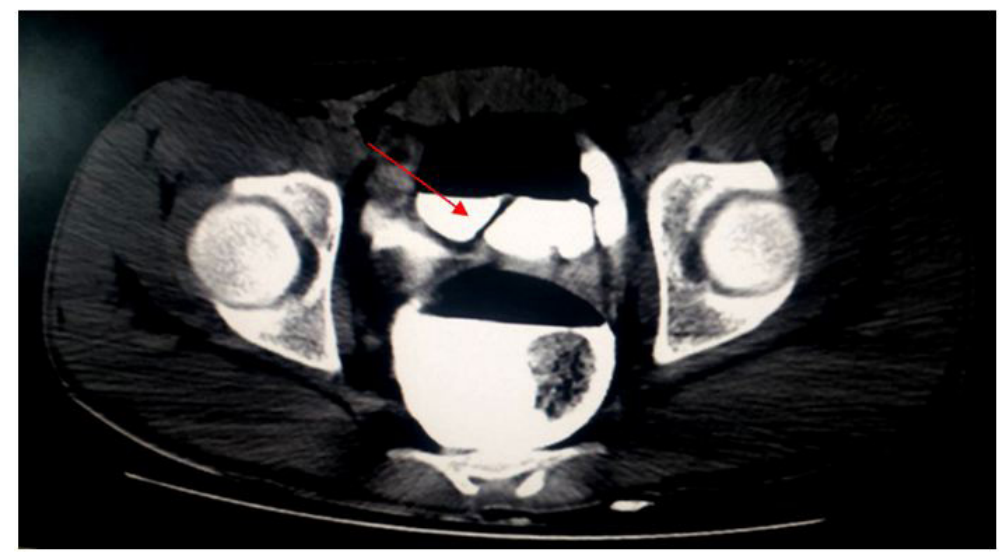

Figure 6: Pelvic scan with rectal opacification of the digestive organs: objectifying a rectal fistula with extravasation of the contrast products (Red arrow) to $6 \mathrm{~cm}$ from the anal margin 
A perineal examination was needed, found perianal redness, without anal fistula or pus or blood, the rectal examination was painful, it objectified a normal sphincter tone, empty rectal cavity, and no rectal bleeding. It should be noted, that the patient being always mute, an interrogation conducted by a psychiatrist highlighted a sexual rape, which could explain the clinical picture.

An antibiotic therapy with a left iliac discharge stoma was urgently carried out; the postoperative consequences were normal, patient put on antibiotic therapy, with clinical and biological supervision for 7 days, if no complications, a restoration of continuity will be scheduled in 2 months. A social worker offered medico-legal care to the family, and a court report was made.

\section{Discussion}

An aeric syndrome in a closed thoraco-abdominal trauma must evoke an aero digestive injury [3]:

- A tracheobronchial rupture, rare at 3\% during closed chest injuries [4], characterized by diffuse cervicothoracic subcutaneous emphysema, associated to pneumothorax and pneumomediastinum, which worsens over time, the key examination remains bronchial fibroscopy, however the case of our patient, he had an aeric syndrome without pneumothorax which was regressive in time at the end of the diet, and bronchoscopy having returned without abnormalities, which derived the etiological diagnosis to a digestive injury

- A rupture of a hollow organ: supra diaphragmatic (esophagus) or sub diaphragmatic (the small intestine in 5 to $10 \%$ of cases, the stomach in $3 \%$ of cases and more rarely the colon or rectum); often secondary to an abdominal contusion that accounts for $80 \%$ of abdominal trauma [5]. 30\% of these ruptures are unknown and diagnosed at a late stage [6].

Pneumomediastinum results in $10 \%$ following cervico-thoracic contusion [7], the diffusion of air is towards the subcutaneous tissue and the spinal canal through the conjugation holes forming a pneumorachis, this one can be isolated during craniofacial trauma [8]. In abdominal injuries the pneumomediastinum is explained by the diffusion through the diaphragmatic openings of pneumoperitoneum that remains present in $28 \%$ of cases during intestinal damage [9].

In our case, the combination of fascia-cervico-thoracoabdominal subcutaneous emphysema, pneumomediastinum, pneumorachis, and pneumoperitoneum thus remains exceptional, testifying to the severity of the trauma. The fact that the clinical examination did not note any thoracoabdominal bruising that made us doubt the traumatic mechanism transmitted by the family.

After the regression of subcutaneous emphysema at the end of the diet, and a normal bronchial fibroscopy, the suspicion of a rupture of a hollow digestive organ was essential, the abdominal CT with pacification of the digestive organs being the gold standard of the diagnostic means [10], and a rectal fistula was objectified.

This prompted us to remake a meticulous interview conducted by a psychiatrist, as long as the patient is still mute and anxious, this has revealed the history of sexual abuse, confirmed by the clinical examination of the perineum which objectified an anal irritation.

Colo-rectal perforations has been reported in the literature during tumoral or diverticular cases, although they are exceptional in abdominal contusions [11], representing less than $1 \%$ of traumatic abdominal lesions and less than $5 \%$ of digestive lesions; the mechanism of this perforation can be by crushing or bursting or direct by a perforating agent [12], that presents the case described above. The perforations following the sexual aggressions are exceptionally reported, their clinical presentation by: a tear of the margin and / or the canal, rectal perforation, rectal hematoma, anal incontinence by internal or external sphincter rupture [13]; this was absent in our case, the things had more complicated the investigation and difficulties to make the correct diagnosis.

\section{Conclusion}

This case emphasizes that careful questioning and a good clinical examination on admission may reveal early the diagnosis, the thing that was not well conducted in our case, because of the patient was mute, anxious, and non-cooperating; which has unnoticed the history of sexual rape, as well as a misconception of the diagnosis, especially with an original clinical picture for a rare organic lesion; exceptional in a traumatic context.

\section{References}

1. Delval O, Fossati P, Tailboux L, Mouillet B, Tallon TB, et al. (1998) Air épidural après traumatisme fermé du thorax. J Radiol 79: 566-8.

2. Hwang WC, Kim HC (2000) CT demonstration of spinal epi-dural air after chest trauma. Eur Radiol 10: 396-7.

3. Neal MD, Sippey M, Gaines BA, Hackam DJ (2009) Presence of pneumomediastinum after blunt trauma in children: what does it really mean? J Pediatr Surg 44: $1322-7$.

4. Kunisch-Hoppe M, Hoppe M, Rauber K, Popella C, Rau WS (2000) Tracheal rupture caused by blunt chest trauma: radiological and clinical features. Eur Radiol 10: 480-3.

5. Sales JP (2002) Management of broken hollow organs during closed trauma of the abdomen. General Surgery Service [Prise en charge des ruptures d'organes creux lors des traumatismes fermés de l'abdomen. Service de Chirurgie Générale]. Hôpital de Bicêtre, France.

6. Barth X, Gruner L (2001) Les méthodes de diagnostic dan sles contusions, dans Traumatismes de l’abdomen, rapport du 103e Congrès Français de Chirurgie, Arnette Paris, France.

7. Cyrlak D, Milne EN, Imray TJ (1984) Pneumomediastinum: a diagnostic problem. Crit Rev Diagn Imaging 23: 75-117. 
8. Rogers LF (1992) Radiology of skeletal trauma (2 ${ }^{\text {nd }}$ Edn) New York: Churchill Livingstone, USA.

9. Cunningham MA, Tyroch AH, Kaups KL, Davis JW (1988) Does free fluid on abdominal computed tomographic scan after blunt trauma require laparotomy? J Trauma 44: 599-603.

10. Nastanski F, Cohen A, Lush SP, DiStante A, Theuer CP (2001) The role of oral contrast administration immediately prior to the computed tomographic evaluation of the blunt trauma victim. Injury 32: 545-9.

11. Pretre R, Rohner A (1992) Pneumomediastinum and subcuta-neous cervical emphysema as signs of rectosigmoid perforation. Gastroenterol Clin Biol 16: 460-2.

12. Blayac PM, Kessler N, Lesnik A, Lopez FM, Bruel JP, et al. (2002) Traumatismes du tube digestif. Encycl Méd Chir (Editions Scientifiques et Médicales), Radiodiagnostic - Appareil digestif, 33-016-A-40. Paris : Elsevier SAS, 2002.

13. Chen YM, Davis M, Ott DJ (1986) Traumatic rectal hematoma following anal rape. Ann Emerg Med 15: 850-2.

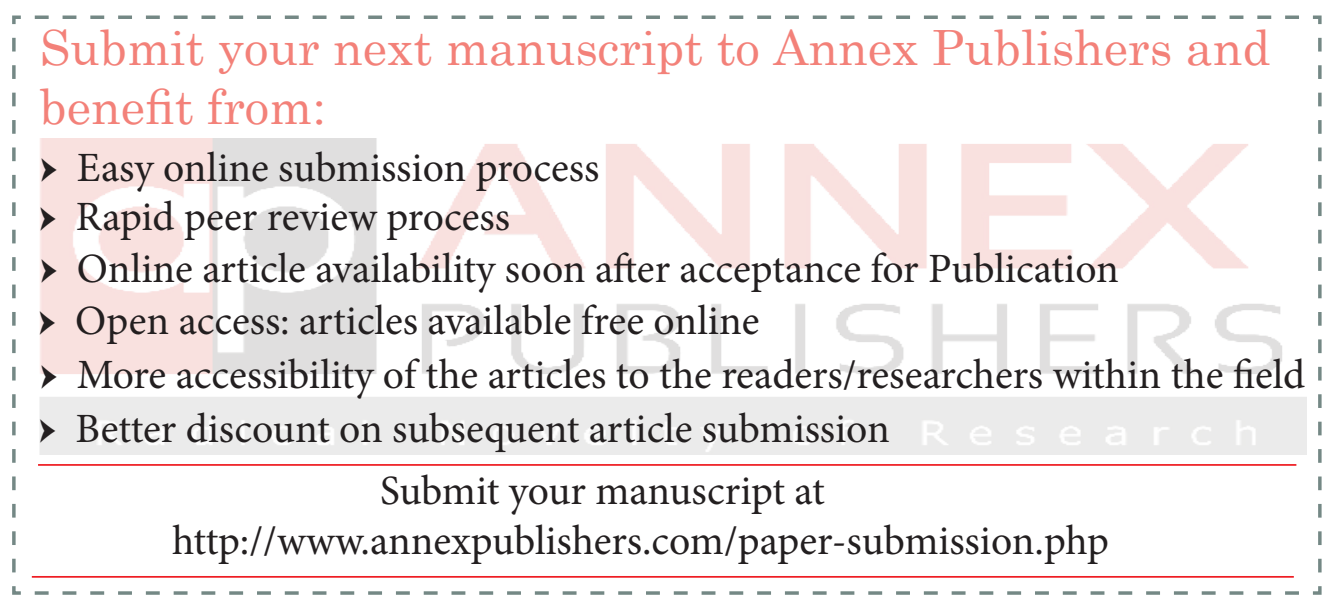

